\title{
Instituto Alan G. MacDiarmid de Inovação e Negócios
}

\begin{abstract}
A criação do "Instituto Alan G. MacDiarmid de Inovação e Negócios" em São Carlos/SP, nasceu com a proposta de estabelecer um esforço arrojado para alavancar inovações e negócios utilizando a experiência da Embrapa Instrumentação Agropecuária, baseada na cooperação internacional e nas parcerias com outras instituições de ensino, de pesquisa e com a iniciativa privada.
\end{abstract}

O Instituto Alan G. MacDiarmid de Inovação e Negócios foi inaugurado no dia 15 de abril deste ano, na Embrapa Instrumentação Agropecuária, em São Carlos/ SP, com a presença do Presidente da Embrapa, Prof. Silvio Crestana, de grande número de autoridades e também do Professor que cedeu seu nome a este instituto.

Com a aprovação da Lei de Inovação, em dezembro de 2004, a Embrapa Instrumentação Agropecuária reuniu todas as condições para criar este Instituto e servir de arranjo modelo para apoiar a implementação de

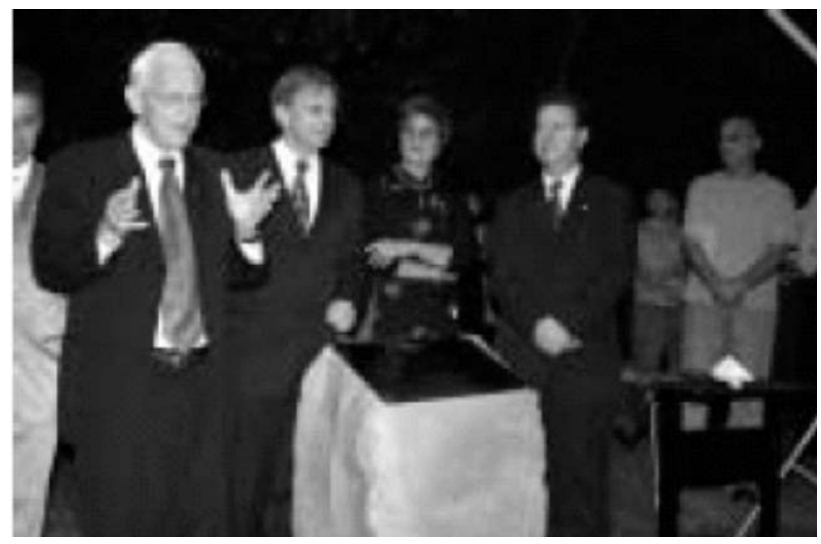
instituições similares em todo o país, ampliando a transferência e incorporação de inovações no agronegócio.

A Embrapa, unidade da Empresa Brasileira de Pesquisa Agropecuária, vinculada ao Ministério da Agricultura, Pecuária e Abastecimento, detém em torno de 60 pedidos de patentes no INPI e já transferiu quase duas dezenas de tecnologias para o setor produtivo. É um dos núcleos-piloto no projeto de apoio à geração de empresas de base tecnológica (PROETA), apoiado pelo Banco Interamericano de Desenvolvimento (BID) e que conta com a parceria da Fundação Parque de Alta Tecnologia de São Carlos. Tem atuado nos últimos anos com uma média de 100 bolsistas de graduação e pós-graduação oriundos de Universidades parceiras (especialmente da USP e UFSCar, de São Carlos). Recentemente, dentro de chamada da Rede Brasil Tecnologia (RBT), do Ministério de Ciência e Tecnologia, a Embrapa Instrumentação Agropecuária teve aprovado cinco novos projetos a serem concluídos em no máximo dois anos. Os projetos são desenvolvidos com empresas privadas interessadas em produzir, em série, as cinco tecnologias que já superaram a fase da pesquisa e que se tornarão inovações disponíveis no mercado. A Unidade participa ainda do relevante esforço do projeto "Rede de Inovação e Prospecção Tecnológica para o Agronegócio (RIPA)", financiado pela FINEP e coordenado pela USP/IEA - São Carlos.

\section{Objetivos do Instituto Alan MacDiarmid}

O Instituto foi inaugurado com a finalidade de:

- Articular os vários segmentos da iniciativa privada e os Institutos de Ciência e Tecnologia para promover inovação, desenvolvimento e negócios para os segmentos agropecuário, florestal e agro-industrial;

- Estimular e apoiar a transferência de tecnologias geradas em Institutos de Ciência e Tecnologia para a iniciativa privada, em sintonia com as novas oportunidades da Lei de Inovação;

- Elaborar cenários, identificando tendências, demandas, vulnerabilidades e oportunidades do agronegócio.

- Fortalecer o estabelecimento de redes cooperativas de Pesquisa, Desenvolvimento e Inovação (P\&D\&I), com atuação multidisciplinar e cooperação internacional.

O Instituto Mac Diarmid terá forte interação com a iniciativa privada e investidores, bem como atuará no âmbito internacional, incluindo cooperações internacionais do mais alto nível com os países desenvolvidos, como a parceria já estabelecida com o Prêmio Nobel Alan MacDiarmid, dos Estados Unidos e com países das regiões dos trópicos, da América do Sul, África e Ásia.

Concretamente, a cooperação com o Prof. MacDiarmid no desenvolvimento de polímeros condutores nanoestruturados resultou no sistema sensor conhecido por "Língua Eletrônica" que, desenvolvido pela Embrapa, recebeu o Prêmio Governador do Estado, na categoria "Invento Brasileiro". Assim, com o decisivo apoio e estímulo do Diretor-Presidente da Embrapa, Silvio Crestana, um entusiasta da inovação, e com o privilégio da cooperação e motivação do Professor Alan G. MacDiarmid, Prêmio Nobel de Química no ano 2000, para ceder seu nome e apoiar o desenvolvimento do re- 
ferido instituto, foi lançada a Pedra Fundamental do "Instituto Alan G. MacDiarmid de Inovação e Negócios", sediado na Embrapa Instrumentação Agropecuária - São Carlos/SP, no dia 15 de maio passado. O Instituto deverá servir de arranjo modelo para apoiar a implementação de instituições similares em todo o país e ampliar a transferência e incorporação de inovações no agronegócio.

Este é o $6^{\circ}$ instituto no mundo com o nome do professor. Já existem na China, Coréia, Índia, Nova Zelândia e Texas, nos Estados Unidos, mas com características diferentes do instituto brasileiro.

O neozelandês naturalizado norte-americano Alan MacDiarmid, nascido em 14 de abril de 1927, recebeu no ano de 2000, junto com os cientistas Alan J. Heeger e Hideki Shirakawa, o Prêmio Nobel de Química pela descoberta e desenvolvimento dos polímeros condutores. Também conhecidos como "metais sintéticos", esses materiais possuem um sem-número de possibilidades de uso na indústria e a Embrapa Instrumentação Agropecuária têm sido pioneira na aplicação dessa tecnologia no desenvolvimento de soluções para o agronegócio.

As primeiras descobertas feitas pelo pesquisador MacDiarmid na área datam de 1973 e ainda hoje, aos 78 anos, ele continua em atividade plena como pesquisador e professor de química da Universidade da Pensilvânia, nos Estados Unidos. Possui mais de 600 trabalhos publicados, cerca de 20 patentes e um longo histórico de colaboração com a Embrapa Instrumentação Agropecuária, através da formação de quadros, pesquisa e desenvolvimento. Uma das tecnologias desenvolvidas com a colaboração do Nobel é a Língua Eletrônica que leva em sua composição polímeros condutores (plásticos que conduzem eletricidade). Os sensores diferenciam sem dificuldade os padrões básicos de paladar, doce, salgado, azedo e amargo, em concentrações abaixo do limite de detecção do ser humano. O sistema também apresenta excelentes resultados na diferenciação de bebidas com o mesmo paladar, sendo possível distinguir diferentes tipos de vinho, café, chá e água mineral. A Língua Eletrônica é dez mil vezes mais sensível que o paladar humano. A pesquisa mais recente desenvolvida em parceria com MacDiarmid envolve a descoberta de sensores à base de plásticos, papel e tecido, com potencial de aplicação para avaliar o estágio de maturação de frutas.

O diretor-presidente da Embrapa, Silvio Crestana, disse que o fato de São Carlos receber o Instituto Alan MacDiarmid, em estreita sintonia com a Embrapa Instrumentação Agropecuária,tem o efeito de "nos deixar extremamente à vontade e confiantes quanto ao sucesso desse empreendimento, pois é como se fora a experiência do Labex às avessas". Segundo ele, é, portanto, um caminho conhecido e desejado por todos, mas sobretudo um caminho que será feito com muito mais experiência e capaz de contribuir para o êxito do empreendimento. "Nos envaidece que seja o primeiro de todos eles a se dedicar à inovação em agricultura", enfatizou Crestana, para quem o Instituto sugere que é significativa a confiança que o professor MacDiarmid deposita na capacidade que a Embrapa tem de compreender os desafios do espaço rural, sobretudo de acessar a dinâmica entre a biodiversidade ambiental e a intervenção produtiva humana, e de aportar soluções criativas para esses desafios. 